\title{
Effect on Stress and Strain of Surrounding Soil by Excavation of Foundation Pit
}

\author{
Shimin Zhang $^{1, \text { a }}$, Yulin He ${ }^{1, b}$, Xinquan Wang ${ }^{1, \mathrm{c}}$ and Miaomiao Sun ${ }^{1, \mathrm{~d}}$ \\ ${ }^{1}$ Zhejiang University City College,China.

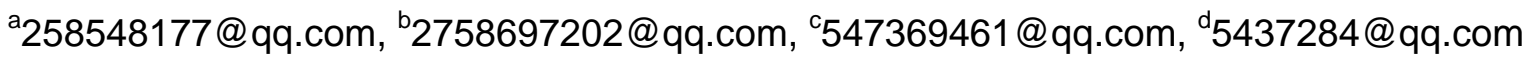

Keywords: Foundation Pit, Stress \& Strain Variation of Surrounding Soil, Displacement of Deep
Soil

\begin{abstract}
It took the project Rainbow Boulevard (Workers Road City Center Road) of Xiaoshan District as the study background and object. Through the monitoring of horizontal displacement of deep soil and the analysis of supporting axial force of steel rebar in different stages of excavation, the rules of stress-strain variation of soil and overall displacement of foundation pits after unloading in different stages of excavation were obtained, thus providing relevant basis for engineering safe design and construction.
\end{abstract}

\section{Preface}

During the past 20 years China's high-rise buildings have developed very quickly. The full use of underground space promotes the development of foundation pits. However the deep foundation pit engineering is still one of the heated and difficult problems in the field of geotechnical engineering. In the current field of foundation pit engineering, the semi-theoretical and semi-empirical method is still adopted. There accident not only affects the stability of the foundation pit and cause economic losses, but also affects the safety of adjacent building near the pits, because the pits may cause the surrounding buildings or underground facilities to crack, tilt or even collapse, resulting in foundation pit accident and personnel casualty. The above facts restrict the development of deep foundation pit engineering. The excavation of the deep foundation pit exerts great effect and disturbance on the soil. Due to the release of soil stress the foundation pit also has influences on the adjacent buildings [1-3]. It affects the foundation of the adjacent buildings, thus affects the upper structure of the building. Therefore, domestic and foreign scholars have carried out a lot of research into the effect on stress and strain of the soil surrounding the excavated foundation pit. This research is carried out based on the existing theory and knowledge in combination with the data of actual measurement at site.

\section{Overview of Foundation Pit}

This project is two-way six-lane open cut tunnel with buried section $354 \mathrm{~m}$ long. The main structure is of single-box double-chamber reinforced concrete box. The clearance size of the tunnel's cross section is $29.1 \mathrm{~m}$ (width) $\times 5.990 \mathrm{~m}$ (height), and the passage size of the unilateral lane is $12.00 \mathrm{~m}$ (width) $\times 5.0 \mathrm{~m}$ (height). The designed excavation depth of the foundation pit is $10.0 \mathrm{~m} \sim 14.20 \mathrm{~m}$. 


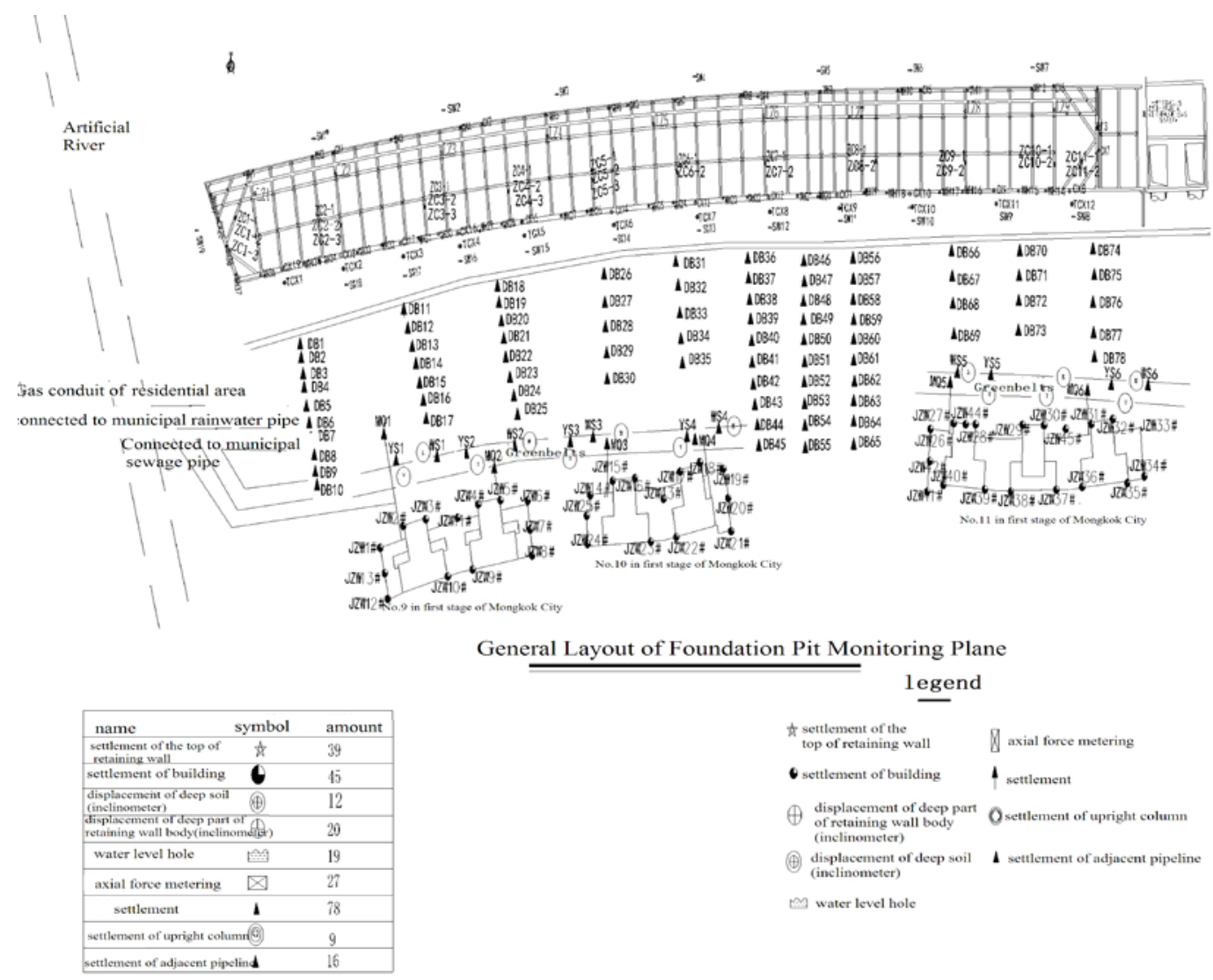

Figure 1. Layout of Foundation Pit Monitoring Point of Rainbow Boulevard of Xiaoshan

Monitoring data: taking the project of Rainbow Boulevard (Workers Road City Center Road) Section A in Xiao District (hereinafter referred to as the XS Project) as the test point.

We selected 19 inclination measurement points around the foundation pit of the XS Project, and respectively took the vertical depth direction as the $\mathrm{Z}$ axis and the direction close to the pit side and vertical to pit boundary as the $\mathrm{Y}$ axis. Daily monitoring was then carried out and inclinometer was utilized to draw the displacement of different inclinometer point in the Y direction during the last one month. At the same time the monitoring data and crack observation data of supporting axial force were collected respectively. Now we randomly select the data for example.

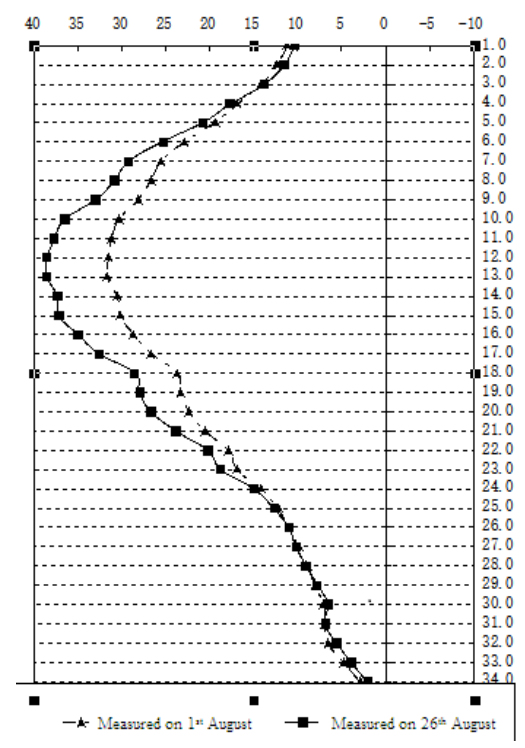

Figure 2 Inclinometer Diagram of Inclination

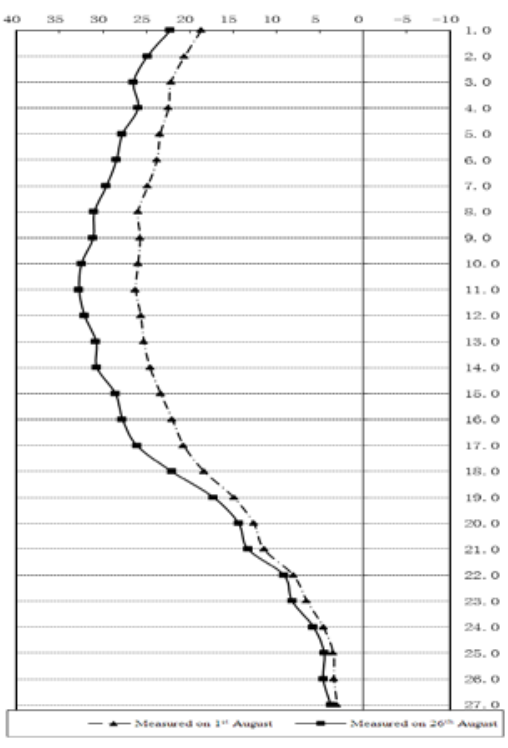

Figure 3 Variation of Axial Force 
We can observe from Fig. 2 Inclinometer Diagram that during the excavation of foundation pit, the horizontal displacement by the middle part of the soil towards inside the foundation is relatively obvious, and the horizontal displacement will reduce whether the depth is increased or decreased. We can observe from Fig. 3 Curve Diagram of Supporting Axial Force that in general the steel support of the first layer bears tensile stress while the steel support of the second layer suffers from compression pressure. [5] This fact leads to ground subsidence. Because of the adhesive force among soil, the movement of soil will destroy the original balance and cause changes to the stress on the horizontal plane of the surrounding soil, finally causing the ground to crack or heave.

We can observe from multiple groups of obtained data that the settlement at the location of 10-16 m below the ground is considerably obvious and the bottom of foundation pit heaves obviously. Mechanical properties of the soil in the excavation process is relatively complex. The excavation process of foundation pit should not be simply regarded as the unloading or loading of one unit of soil. [5]Though the soil may be unloaded or remains unchanged in the vertical direction, it is very difficult to determine whether the soil is loaded or unloaded in the lateral direction. The results of on-site survey of foundation pits prove that the mechanical properties of the soil in the excavation process is relatively complex. In general the excavation process of foundation pit is essentially a process of soil unloading, but sometimes both the loading and unloading conditions may appear at one time. Both the loading and unloading of soil inside the foundation pit can produce certain stress on the surrounding soil in the excavation process. The unloading of the soil inside the foundation pit will cause the surrounding soil to crack and the loading of the soil inside the foundation pit will cause the surrounding soil to be squeezed and cause the ground to heave[1].

The excavation process of foundation pit is the unloading process for the excavation surface of the foundation pit in the vertical direction and for the supporting pile in the horizontal direction. Because of the unloading effect after excavation of foundation pit, horizontal displacement happens to the retaining structure under the pressure of soil, causing the bottom of foundation pit to heave and deform. If foundation pit is not excavated deeply, the heave of the pit bottom is elastic. At this time the heave in the center of the pit bottom is biggest and the heave on two sides is relatively small. [2] If the foundation pit is excavated deeply and widely, the heave of the pit bottom is plastic. At this time the heave in the center of the pit bottom is also bigger than that on the two sides. The lateral displacement of the supporting structure takes place in two forms, the horizontal deformation and vertical deformation respectively. The vertical displacement of enclosure structure is neglected in application of engineering. In fact due to the release of the soil's self-stress during the excavation of foundation pit, the enclosure structure rises, which seriously impacts the overall stability of foundation pit and causes ground subsidence. After the excavation of foundation pit, the ground stress changes and the soil moves. T retaining structure may deform, the bottom of foundation pit will heave, and ground subsidence outside supporting structure can occur, impacting the safety of the surrounding buildings, underground pipe network and traffic facilities.

\section{Analysis of Results}

This paper based the research on the excavation of foundation pit for Rainbow Boulevard in Xiaoshan District. It introduced the geological conditions of the project. in view of the deep foundation pit engineering of foundation pit, horizontal displacement of the foundation pit caused by the excavation process and the crack of surrounding soil as well as the change of axial force of the steel support were monitored. The monitoring results show that in the excavation process the influence on the surrounding soil is controlled within the allowable range. Monitoring results not only reflect the influence on the surrounding soil by excavation of foundation pit, but also reflect the rationality and feasibility of the support method of the project. [4]

\section{Limitation and Outlook of Research}

Regional Nature: the regional nature of foundation pit engineering means the influences of 
geological differences. The geological conditions vary in the different areas. Even in different areas of the same city, the geological conditions have obvious differences.

There are significant differences in the engineering of foundation pits with different geological and hydrogeological conditions, e.g. the foundations of loess, sandy soil, and soft clay. Due to the variance in geotechnical properties, and complexity and imbalance of geological heterogeneity and hydrogeological conditions, the data acquired by survey often have great dispersion, difficult to represent the overall condition of the soil, and the precision is very low.[1]Therefore, the excavation of deep foundation pit shall be based on the local conditions. The specific problems shall be analyzed according to the specific local conditions, and the engineering experience in other regions shall not be simply copied with any modification.

Comprehensive Nature: engineering of deep foundation pit involves 3 basic topics, e.g. Strength of Soil Mechanics (or Stability), Deformation and Seepage. The existence of the three issues requires a comprehensive solution. For some foundation pits the main issue is that the pressure of soil impacts the stability of retaining structure. For some foundation pits the principal issue is associated with the damage to soil by seepage while for other foundation pits the major concern is the deformation of ground around the pit. The engineering of deep foundation pit is a cross-discipline involving geotechnical engineering, structural engineering and construction technology. It is a systematic works influenced by various complicated factors. It's one comprehensive technical theory which has yet to be developed. This paper does not propose solutions to most of the issues associated with foundation pit, thus the research is not comprehensive enough.

\section{Outlook}

This research analyzed the monitoring data and obtained the basic rules of deformation of deep foundation pit. It is worth to further study how to use the monitoring data to optimize the design scheme of existing retaining structure.

The properties of soil vary in different places. It is worth to further study how to make use of the research into the stress and strain of soil to get the mechanical properties of other soils (they are the same more or less) in order to provide basis for the engineering of foundation pits.

\section{Acknowledgements}

This work was financially supported by the Science Technology Department of Zhejiang Province(2013C31041), Ministry of Hosing and Urban-Rural of Zhejiang Province (2014Z099), and Zhejiang University City College (J-15017).

\section{References}

[1] Jialiang Yan, in: The characteristics of excavation of foundation pit surrounding soil displacement effect of complex factors, edited by China Municipal Engineering Vol. 2014(1)

[2] Xunnan Tu, in: A Brief Analysis of Deep Excavation Slope Based on Stress and Strain Relation, edited by Real Estate Biweekly Vol. 2014(15)

[3]Linguo Li, in: Analysis of Excavation of Soil Stress Condition and Stress Path, edited by Heilongjiang Science and Technology Information Vol. 2009(12)

[4] Wang Zhiguang, in: Analysis on the foundation pit excavation soil mechanical problems related characteristics, edited by Sichuan Building Materials Vol. 2008,34(1)

[5] Liu Guobin, Liu Jinyuan and Xu Quanqing, in: Experimental study on variation of mechanical characteristics of soil due to excavation, edited by Chinese Journal of Rock Mechanics and Engineering Vol. 2000,19(1) 